To appear in Philosophical Magazine Letters

Vol. 00, No. 00, Month 20XX, 1-8

\title{
Etch pitting and subsurface pore growth during the thermal etching of silver
}

\author{
M. Ollivier ${ }^{\mathrm{a}}$, R.M. Harker ${ }^{\mathrm{b}}$ and C.M. Gourlay ${ }^{\mathrm{a}}$ \\ ${ }^{a}$ Department of Materials, Imperial College London, SW7 2AZ, UK; \\ ${ }^{b} A W E$ Aldermaston, Aldermaston, Reading, RG' 4PR, UK
}

(Received 00 Month 20XX; accepted 00 Month 20XX)

\begin{abstract}
The thermal etching of silver was extensively studied in the middle of $\mathrm{XX}^{\text {th }}$ century, revealing the key role of oxygen on surface morphology changes including: grains striation, grain-boundary grooving and etch pitting. Here we probe the role of the subsurface and defects induced by rolling on the thermal etching of pure silver sheet. Nanometre and micrometre sized faceted pores have been observed in the subsurface region after heat treatments in air. The relationship between these subsurface pores and rolling defects is demonstrated. A mechanism for the formation of subsurface pores based on the precipitation/reaction of dissolved oxygen is suggested which can also explain the aligned etch pitting observed.
\end{abstract}

Keywords: Silver; Surface; Etch pitting; Striations; Grooving; Subsurface; FIB-SEM; Pores.

\section{Introduction}

Silver is an important metal for the chemical industry and is used as a catalyst in numerous chemical reactions such as the epoxidation of ethylene or the partial oxidation of methanol to formaldehyde. Utilised at relatively high temperatures e.g. $647^{\circ} \mathrm{C}$ for the partial oxidation of methanol to formaldehyde-, these processes depend on the interactions of molecules with the silver surface. Yet, when silver is heated its surface undergoes pronounced morphological changes including grain striation, grain-boundary grooving and etch pitting. These changes are generally gathered under the term "thermal etching", and were widely studied in the middle of the $\mathrm{XX}^{\text {th }}$ century. It is widely accepted that the surface reconstructions are driven by the reduction in free surface energy coupled with possible evaporation and reaction processes [1-3]. However a large set of extrinsic parameters can impact on the development of these morphologies: atmosphere surrounding the surface, time and temperature of heat treatments, applied stress, or impurities in metal [4]. The results presented in this letter, obtained by applying modern characterisation tools to the study of thermal etching of industrial sheets of silver reveal the importance of defects induced by rolling on the morphologies developed.

${ }^{*}$ Corresponding author. Email: o.maelig@imperial.co.uk 


\section{Experimental details}

Laboratory polished surfaces will not be representative of silver surfaces used in an industrial context. For this reason we chose to study the as-received (but cleaned) surface direct from the manufacturer. The cm-squared samples of pure silver $(99.99 \%$, grain size $20 \mu \mathrm{m}, \mathrm{O} \approx 20 \mathrm{wtppm})$ were then collected on silver sheet previously processed as follows: after a first rolling step decreasing the thickness from $15 \mathrm{~mm}$ to $2 \mathrm{~mm}$, the silver sheet is annealed in a reducing atmosphere for $45 \mathrm{~min}$ at $650^{\circ} \mathrm{C}$ then straightened and brushed. A second rolling step is carried out crosswise to decrease the thickness down to $0.7 \mathrm{~mm}$ followed by another annealing in a reducing atmosphere for $45 \mathrm{~min}$ at $650^{\circ} \mathrm{C}$. Finally the silver sheet is rolled down to $0.5 \mathrm{~mm}$ then annealed in an inert atmosphere at $350^{\circ} \mathrm{C}$ for 4 hours.

Thus, the experimental part of this study lies on heat treatment experiments on these samples in air at atmospheric pressure and at different temperatures (from 400 to $800^{\circ} \mathrm{C}$ ) and different dwell times (from 60 to $720 \mathrm{~min}$ ). A hot wall horizontal furnace (alumina tube open at both ends) has been used for heat treatments. The surface of the as-treated silver was then characterised by Scanning Electron Microscopy (FEG-SEM, Zeiss Auriga) and Energy Dispersive X-ray spectroscopy (EDX, Oxford Instruments). The subsurface was also investigated by dual column focussed ion beam/SEM microscopy (FIB-SEM, FEI Helios NanoLab 600).

Since this study is particularly interested in the silver surface and the morphology in the immediate subsurface, we gave careful consideration to surface cleanliness. Our silver was shown to be contaminated with organic pollutants (grease, fingerprints), particles coming from manufacturing tools and corrosion products such as $\mathrm{Ag}_{2} \mathrm{~S}[5,6]$. Silver corrosion is a well-studied phenomenon where pollutants such as carbonyl sulfide (COS), hydrogen sulfide $\mathrm{H}_{2} \mathrm{~S}$ and dimethyldisulfide $\mathrm{Me}_{2} \mathrm{~S}_{2}$, enhanced by humidity $\left(\mathrm{H}_{2} \mathrm{O}\right)$, react with silver surfaces to produce mainly acanthite $\mathrm{Ag}_{2} \mathrm{~S}$ following reaction 1 where ions $\mathrm{Ag}^{+}$and $\mathrm{S}^{2-}$ are produced by oxido-reduction in the presence of $\mathrm{H}_{2} \mathrm{O}[7-9]$.

$$
2 \mathrm{Ag}_{(\mathrm{aq})}^{+}+\mathrm{S}_{(\mathrm{aq})}^{2-} \longrightarrow \mathrm{Ag}_{2} \mathrm{~S}_{(\mathrm{s})}
$$

The cleaning process proposed here is then made of two steps.

Firstly, $1 \mathrm{~cm}^{2}$ silver coupons are put in contact with an aluminum foil in a potassium hydroxide solution $\mathrm{KOH}: \mathrm{H}_{2} \mathrm{O}\left(0.6 \mathrm{~mol} . \mathrm{L}^{-1}\right)$ heated at $80^{\circ} \mathrm{C}$ for $2 \mathrm{~min}$. In this step silver sulphide is decomposed according to the oxido-reduction reaction outlined in reaction 2. Samples are then rinsed with deionised water and dried;

$$
3 \mathrm{Ag}_{2} \mathrm{~S}+2 \mathrm{Al}+6 \mathrm{H}^{+} \longrightarrow 6 \mathrm{Ag}+2 \mathrm{Al}_{3}{ }^{+}+2 \mathrm{H}_{2} \mathrm{~S}
$$

In order to remove any organic pollutants and dust, the second step is made of three sonications of 10 min using acetone $\left(\mathrm{CH}_{3} \mathrm{COCH}_{3}\right)$, methanol $\left(\mathrm{CH}_{3} \mathrm{OH}\right)$ and isopropanol $\left(\mathrm{CH}_{3} \mathrm{CH}(\mathrm{OH})-\mathrm{CH}_{3}\right)$. Silver samples are then rinsed with isopropanol and directly inserted into the furnace. 
A typical surface of silver samples cleaned by this process is presented Figure 1. Firstly no silver sulphides remain at the surface but 10-20 nm diam. pores due to silver sulphide removal can be found especially on highly contaminated samples. Also, some carbon contamination can still be found trapped on the surface of silver forming strips over $100 \mu \mathrm{m}$ length scales (see Figure 1(a)) along the rolling direction. This carbon contamination lines are coincident with smaller grains found in that region (see inset Figure 1(a)). Under these strips subsurface carbon-rich impurities have been identified after FIB milling (see cross-section SEM image Figure 1(b) and related EDX spectrum Figure $1(\mathrm{c})$ ). These features have size of $\approx 40 \mathrm{~nm}$ and are found at a depth of $\approx 0-0.5 \mu \mathrm{m}$ from the free surface. Most of these features cannot be satisfactorily resolved due to their size but the larger features are not faceted and are shown to be rich in $\mathrm{C}$ by EDX.

Similar subsurface layers with smaller grains and cavities filled with impurities have already been reported in the case of hot-rolled aluminum alloys [10, 11]. Furthermore the trapping of lubricant into pits during the cold-rolling of stainless steel has been well studied in order to improve the surface finish of commercial strips [12, 13]. Based on these points, we attribute the surface lines of carbon contamination, surface lines of smaller grains and subsurface contamination in these regions to defects induced by rolling. Note that C-contamination and subsurface impurity particles vary from batch to batch, but these phenomena are widespread in rolling [10-13] and are likely to exist to differing degrees in industrially-used $\mathrm{Ag}$ sheet.



(a) Surface

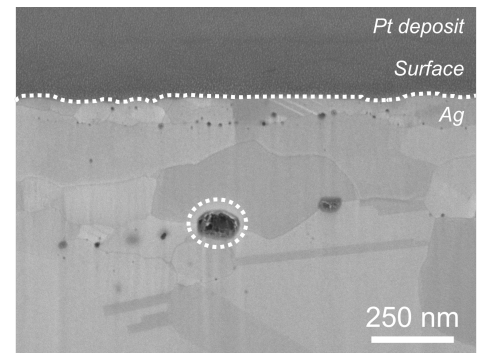

(b) Cross-section



(c) EDX spectrum

Figure 1.: (a) SEM image of the surface of silver after cleaning process. (b) FIB crosssectioned SEM image of silver with a subsurface carbon-rich particle highlighted. (c) EDX spectrum of the carbon-rich feature ringed in (b) (accelerating voltage $20 \mathrm{keV})$. 


\section{Results and discussion}

SEM observations of silver surfaces after heat treatments in air reveal some of the morphologies expected from the literature. For example, grain boundary grooving (see Figure 2(a)) and striation development (see Figure 2(c)) at higher temperatures and longer annealing times. Grain-boundary grooving and grain striation can be seen as intrinsic phenomena, and have been explained by the reduction in free surface energy, kinetics of evaporation and the effect of an $\mathrm{O}_{2}$-rich atmosphere. A formalism of grain-boundary grooving has been suggested by Mullins et al. $[14,15]$ for instance, and striation of a flat surface with a constant average orientation is well described by the polar $\gamma$-plot of surface energy $[4,16]$.

In addition, etch pits were observed over all conditions studied here $\left(400-800^{\circ} \mathrm{C}\right.$; 60-720 min) in lines over mm length scales crossing many grains (see for example Figure 2(i)). Internal surfaces of the etch pits were faceted and terraced with crystallographic faces (see inset on Figures 2(a), 2(e) and 2(i)). The lines of etch pits were coincident with the contamination lines observed before heat treatment (see Figure 1(a)) or close to these lines. Thus a natural conclusion is that the presence of aligned etch pits after heat treatment is the result of residual defects induced by the rolling procedure.

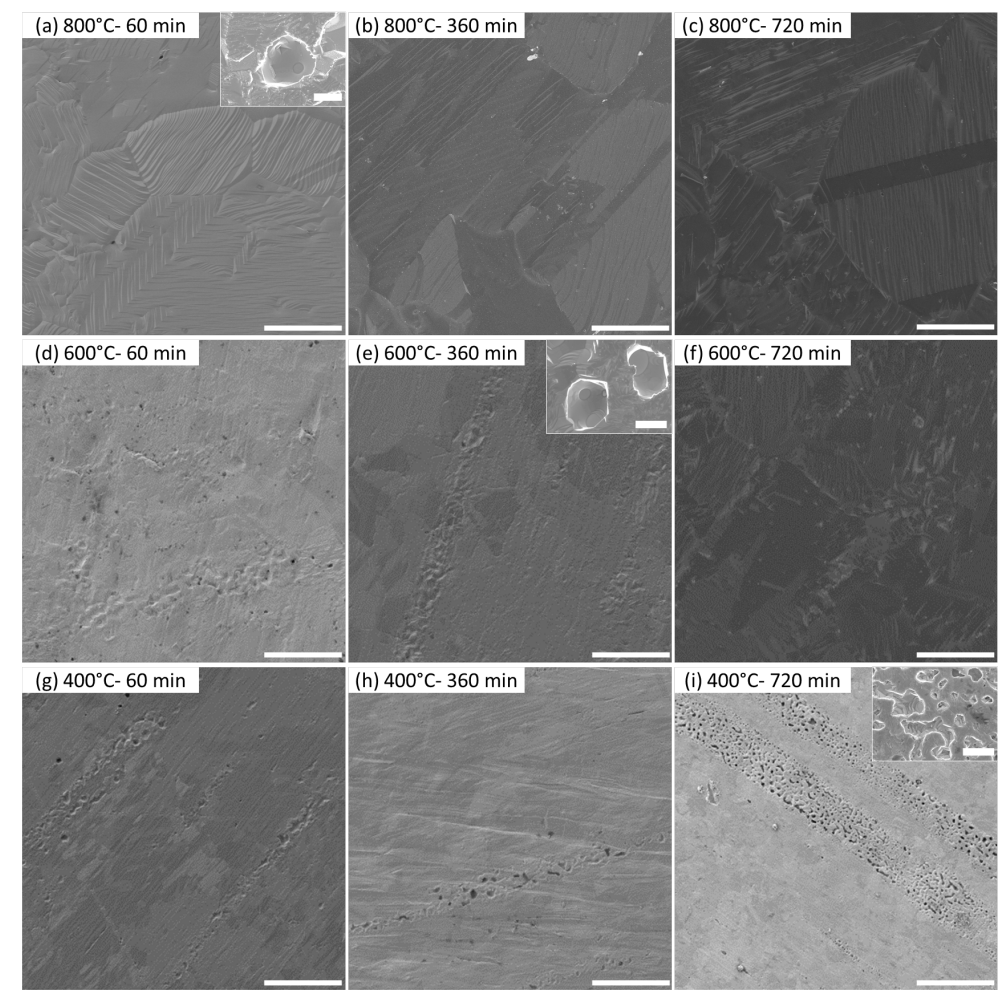

Figure 2.: SEM images of silver surface after different heat treatments in air. Temperature range 400 to $800^{\circ} \mathrm{C}$; dwell time from $60 \mathrm{~min}$ to $720 \mathrm{~min}$. Scale bars $=20 \mu \mathrm{m}$ and $1 \mu \mathrm{m}$ for inset SEM images. 
In order to understand the subsurface reconstruction, cross-sectional SEM imaging after FIB milling have been performed, both parallel (Figures 3(a)-(e)) and perpendicular (Figure 3(f)) to the lines of etch pits. Faceted pores have been found in the subsurface region, essentially in the vicinity of surface etch pits but generally at a depth of $0.1-1.0 \mu \mathrm{m}$ and not deeper than $2 \mu \mathrm{m}$ from the surface. The size of these pores increases with temperature, as can be seen comparing SEM images on Figures 3(a)-(e). The localisation of these pores under etch pits is shown on the SEM image in Figure 3(f) where a line of pits has been indicated (dotted lines) as well as on Figure 3(e) where a subsurface pore and an etch pit have been highlighted. These faceted pores display complex facets as shown on Figures $3(\mathrm{~g})-(\mathrm{h})$, where SEM images of silver heat treated at $800^{\circ} \mathrm{C}$ for $60 \mathrm{~min}$ are shown. Also, pores intersecting the surface can be found as shown in Figure 3(i); the surface is highlighted with a dotted line. This suggests that the formation of these pores in the subsurface region may be a source of etch pitting when these latter reach the surface. To explore this further slice \& view FIB/SEM experiments were performed on all samples presented Figure 2.

A typical movie of a slice \& view FIB/SEM experiment is shown as Supplementary Material. This silver sample was heated for $6 \mathrm{hrs}$ at $800^{\circ} \mathrm{C}$ in air at atmospheric pressure (see the surface on Figure 2(e)). The milling is parallel to a line of etch pits, with a milling step of $\approx 100 \mathrm{~nm}$ and a $500 \mathrm{~nm}$-thick ion beam-induced $\mathrm{Pt}$ deposit is used as a protective layer. It can be seen that there are numerous pores 1-2 $\mu \mathrm{m}$ from the surface, that most of these pores do not intersect the surface, and that there are no pores at depths greater than $\approx 2 \mu \mathrm{m}$ from the surface. Also, one pore intersects the surface but is otherwise not distinguishable from a subsurface pore, which strongly suggests that this "etch pit" is a pore that grew to intersect the surface. Note that past studies on the thermal etching of silver have used optical microscopy and/or SEM and, therefore, were unable to detect these subsurface pores. As a test, silver samples were polished prior to heat treatments, typically with aqueous suspensions of successively finer grades of polycrystalline diamonds down to $0.25 \mu \mathrm{m}$, in order to remove the subsurface region and carbon contamination. Interestingly, no etch pits were observed on these polished samples after heat treatments in air at atmospheric pressure.

In the literature, etch pitting during thermal or chemical etching is mainly described in terms of dislocations revelation [17-20]. However in our case, the localisation and alignment of etch pits is directly related to strips of carbon contamination with smaller grains and is unlikely to be explained only by dislocations. Our observations are thus closer to the work of Vanselow et al. [21] where etch pits have been found nucleating preferentially on lattice imperfections (grain boundaries, twin boundaries, etc). However, the growth of pores in the subsurface region and parallel to the lines of carbon contamination suggests a new and additional mechanism that leads to aligned etch pitting: these etch pits are likely to be subsurface pores that grew to intersect the surface (Figure 3 and the movie displayed as Supplementary Material).

The observation of pores in the subsurface region occurring during thermal treatments of laboratory polished silver has been briefly described in the literature by Klueh \& Mullins [22, 23] as well as by Bao et al. [24]. However, the suggested ex- 

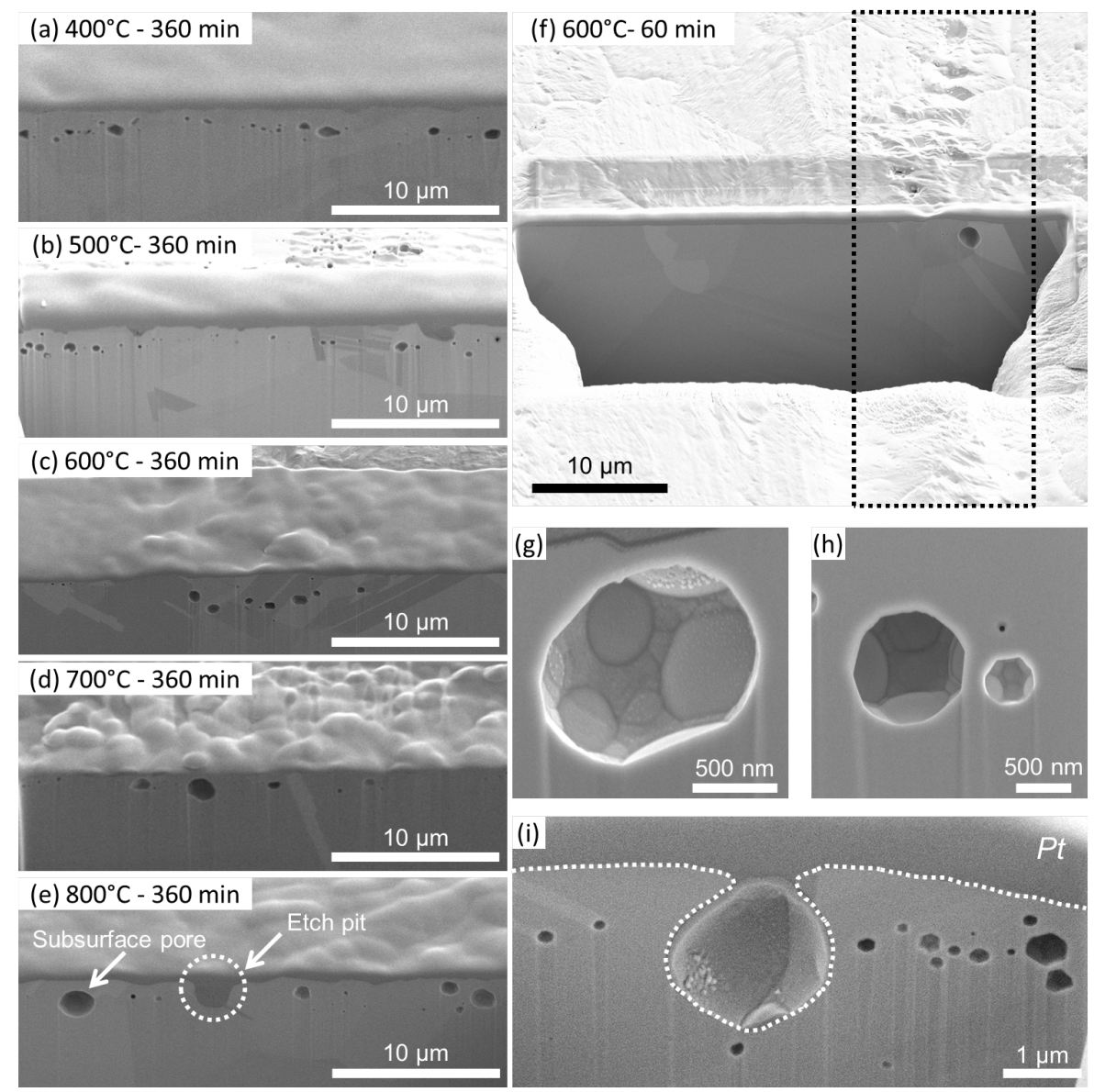

$10 \mu \mathrm{m}$

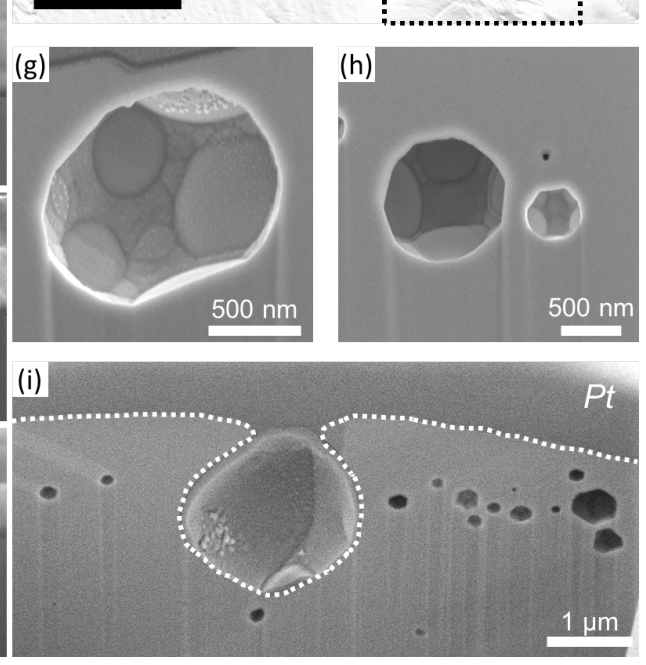

Figure 3.: SEM images of the subsurface region of silver samples after heat treatments in air. (a)-(e) Cross-sections after FIB milling parallel to the lines of etch pits on silver samples heated at different temperatures; platinum deposits used to limit damage during milling are observable (tilt angle $52^{\circ}$ ). (f) Subsurface pores are found in the same region as surface etch pits (a line of etch pits is highlighted with dot lines); tilt angle $52^{\circ}$; FIB milling perpendicular to the line of etch pits. (g)-(h) High magnification SEM images of faceted pores found under the surface of a silver sample annealed in air for $60 \mathrm{~min}$ at $800^{\circ} \mathrm{C}$. (i) Cross-section after FIB milling of a pore connected with the surface of a silver sample heat treated in air for $720 \mathrm{~min}$ at $800^{\circ} \mathrm{C}$, the surface is highlighted with a dotted line.

planation for these voids requires a heat treatment in a $\mathrm{H}_{2}$ and $\mathrm{O}_{2}$-rich atmosphere leading to the dissolution of $\mathrm{H}$ and $\mathrm{O}$ in the silver, followed by the formation of water vapour in the subsurface termed the Liesgang phenomenon [25]. This is not relevant in our case, although the impact of oxygen in the nucleation and growth of subsurface pores has been confirmed by heat treatment experiments identical to those presented in this letter, but with an inert atmosphere (atmospheric argon). Finally, it can be noted that faceted voids in solids have already been studied both theoretically and experimentally by Nelson et al. [26]: sub-micron bubbles were observed in metal foils previously bombarded with inert gases and then heated.

It is probable that multiple mechanisms combine to produce the nucleation and growth of subsurface pores. The formation of the faceted pores found may be due 
to the coalescence of vacancies however, the diameter of these pores -up to $2 \mu \mathrm{m}-$ is not compatible with this assumption since a high vacancy density localised in the subsurface region should be necessary. A second hypothesis based on the precipitation of oxygen atoms dissolved into silver and reaction of oxygen with carbon contamination is more likely to be true. Indeed, the heat treatments have been carried out in an oxygen-rich atmosphere and no carbon contamination is observable after heat treatment. Finally, the nucleation of such pores may be facilitated by the defect densities found in carbon contamination/smaller grains strips presented Figure 1 as well as at annealing twin boundaries formed during heat treatment.

\section{Conclusions}

An experimental study on surface and subsurface changes during heat treatments of rolled silver sheet has been conducted, utilizing a focused ion beam (FIB) coupled with scanning electron microscopy. A non-destructive cleaning process has been applied to the surface of the rolled and annealed sheet and heat treatments in air have been performed. Among the well-known features grouped together under the term thermal etching, a closer study of etch pitting has been carried out. These etch pits, are found in lines of mm length crossing many grains and are coincident with strips of carbon contamination/smaller grains seen on silver samples before heat treatments. FIB/SEM slice \& view characterisation of the same regions revealed the presence of faceted pores in the subsurface $(\approx 0.2-1 \mu \mathrm{m}$ deep). These pores may originate from the precipitation/reaction of dissolved oxygen in silver and be the source of etch pitting when reaching the surface. This shows that the subsurface plays a key-role in thermal etch pitting and thus should be taken into account to explain the modification of silver surfaces in industrial applications.

\section{References}

[1] B. Chalmers, R. King and R. Shuttleworth, Proceedings of the Royal Society of London. Series A, Mathematical and Physical Sciences 193 (1948) p. 465.

[2] G. Rhead and H. Mykura, Acta Metallurgica 10 (1962) p. 843.

[3] A. Moore, Metal Surfaces: Structure, Energetics and Kinetics. Papers Presented at a Joint Seminar of the American Society for Metals and the Metallurgical Society of AIME, October 27 and 28, 1962, Vol. 5, American Society for Metals, 1963.

[4] M. Flytzani-Stephanopoulos and L. Schmidt, Progress in Surface Science 9 (1979) p. 83.

[5] H. Aguas, R.J.C. Silva, M. Viegas, L. Pereira, E. Fortunato and R. Martins, Physica Status Solidi (c) 5 (2008) p. 1215.

[6] H. Lin, G.S. Frankel and W. Abbott, Journal of the Electrochemical Society 160 (2013) p. C345.

[7] D. Rice, R. Cappell, W. Kinsolving and J. Laskowski, Journal of The Electrochemical Society 127 (1980) p. 891.

[8] T. Graedel, Journal of The Electrochemical Society 139 (1992) p. 1963.

[9] V. Costa, Studies in Conservation 46 (2001) p. 18.

[10] M. Fishkis and J. Lin, Wear 206 (1997) p. 156.

[11] G. Buytaert, H. Terryn, S. Van Gils, B. Kernig, B. Grzemba and M. Mertens, Surface and Interface Analysis 38 (2006) p. 272.

[12] J. Bech, N. Bay and M. Eriksen, Wear 232 (1999) p. 134.

[13] R. Ahmed and M. Sutcliffe, Wear 244 (2000) p. 60.

[14] W. Mullins, Journal of Applied Physics 28 (1957) p. 333. 
[15] W. Mullins and P. Shewmon, Acta Metallurgica 7 (1959) p. 163.

[16] C. Herring, Physical Review 82 (1951) p. 87.

[17] A. Hendrickson and E. Machlin, Acta Metallurgica 3 (1955) p. 64.

[18] J. Hirth and L. Vassamillet, Journal of Applied Physics 29 (1958) p. 595.

[19] H. Levinstein and W. Robinson, Journal of Applied Physics 33 (1962) p. 3149.

[20] C. Chen and A. Hendrickson, Journal of Applied Physics 42 (1971) p. 2208.

[21] R. Vanselow, R. Masters and R. Wehnes, Applied Physics 12 (1977) p. 341.

[22] R. Klueh and W. Mullins, Acta Metallurgica 17 (1969) p. 59.

[23] R. Klueh and W. Mullins, Acta Metallurgica 17 (1969) p. 69.

[24] X. Bao, G. Lehmpfuhl, G. Weinberg, R. Schlogl and G. Ertl, Journal of the Chemical Society-Faraday Transactions 88 (1992) p. 865.

[25] C. Wagner, Journal of Colloid Science 5 (1950) p. 85.

[26] R. Nelson, D. Mazey and R. Barnes, Philosophical Magazine 11 (1965) p. 91. 